\title{
COMMISSION 6: ASTRONOMICAL TELEGRAMS (TÉLÉGRAMMES ASTRONOMIQUES)
}

\author{
Report of Meeting, 21 August 1970
}

President: F. L. Whipple.

SECRETARY: B. G. Marsden.

The Commission approved the election of P. Simon as incoming President and J. Hers as incoming Vice-President. A. Mrkos and Y. Kozai were elected as new members, the former to replace E. Buchar, who was retiring from the Commission because of ill-health.

Noting that the request for an IAU subvention to the Central Telegram Bureau of $\$ 1600$ for the triennium 1971-3 had already been submitted to the Finance Committee*, the President remarked that the Smithsonian Astrophysical Observatory continued to subsidize the Bureau's operation, although now almost entirely in the form of personnel. He was pleased to see that Miss Virginia Lincoln was present at the meeting and expressed the appreciation of the Commission for the great service performed by the International Ursigram and World Day Service in relaying the Bureau's telegrams.

The President also mentioned that, in the United States at any rate, the telegram was fast becoming a dying institution, and the Secretary circulated a recent newspaper item on this subject. While the Commission should not at present be too alarmed by this development, it was suggested that some initial thought be given to the possible future impact on the work of the Central Bureau. The trend is toward the increased use of the telex system and possibly the introduction of 'mailgrams', where a telegraph company telephones the contents of a telegram to the postmaster in the recipient's town, the postmaster then forwarding the message by mail.

Since his presence was simultaneously required at another meeting the President at this point invited the new President, Dr Simon, to take the Chair.

Dr Marsden reported that, contrary to the hope expressed in Trans. IAU XIVA, 16, the billing for the Circulars had not yet been changed to a yearly basis. Part of the reason for this was that there had been frequent changes in the secretarial assistance available to the Central Bureau; the matter was still very much under consideration, however, and he was confident that the desired change would be made before too long.

The seemingly trivial problem was brought up as to a suitable character to indicate that certain information was being suppressed from an astronomical telegram. Some telegraph companies were taking it upon themselves to suppress this character itself or even the whole group containing it. After some discussion by O. J. Gingerich, J. V. Lincoln, B. G. Marsden, E. Roemer and P. Simon and consideration also of a suggestion sent by J. Hers it was agreed that, while the choice was not perfect, and it would thus be inadvisable to make an official change in the code, the Central Bureau should for the time being experiment by indicating a suppressed digit by a slash (/).

Dr Marsden remarked that he felt that, since the Bureau had issued more than 100 Circulars during the previous twelve months, it should be more strict concerning the items accepted for publication. A decision had already been made concerning the Bureau's intention to limit the number of precise positions of comets that were published, but it was also true that many other items, while often referring to topics of great astronomical interest (e.g. pulsars), were better suited for publication in other media. Several others attending the meeting, however, expressed their pleasure at acquiring from the Circulars immediate, reliable information on such topics.

* and was approved; see the report of the Finance Committee. 